\title{
Relationship between the mechanical properties of epoxy/PMMA-b-PnBA-b-PMMA block copolymer blends and their three-dimensional nanostructures
}

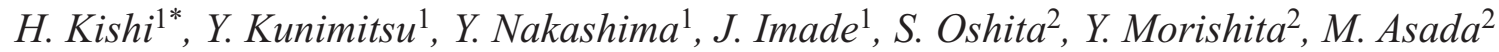 \\ ${ }^{1}$ Graduate School of Engineering, University of Hyogo, 2167, Shosha, Himeji, 671-2201 Hyogo, Japan \\ ${ }^{2}$ Kuraray Co. Ltd., 1-1-3, Otemachi, Chiyoda-ku, 100-8115 Tokyo, Japan
}

Received 9 February 2017; accepted in revised form 26 April 2017

\begin{abstract}
Nanostructures of diglycidyl ether of bisphenol-A epoxy/poly(methyl methacrylate)- $b$-poly(n-butyl acrylate)- $b$ poly(methyl methacrylate) (PMMA- $b$-PnBA- $b$-PMMA) triblock copolymer (BCP) blends were studied in relation to their mechanical properties. Three types of self-assembled nanostructures, such as spheres, random cylinders, and curved lamella, were controlled in phenol novolac-cured epoxy blends with a wide range of BCP content. Three types of nanostructures were observed using two-dimensional and three-dimensional transmission electron microscopy (TEM). The 3D-TEM, dynamic viscoelastic analyses, and theoretical model on the elastic modulus clarified that the spheres and the random cylinders, consisted of epoxy-immiscible PnBA phases, were discontinuously dispersed in the epoxy matrix. In contrast, the curved lamella formed co-continuous nanostructure, in which both the PnBA and epoxy phases formed continuous channels. The fracture toughness (critical strain energy release rate, $G_{\mathrm{IC}}$ ) and the flexural moduli of elasticity $(E)$ of the cured blends were evaluated for various amounts of BCP content. The highest $G_{\mathrm{IC}}$ was obtained from the random cylindrical nanostructured blends in the three types of nanostructures with the same PnBA content. The lowest $E$ was obtained for the curved lamella with co-continuous nanostructures. The details of deformation and fracture events were observed using optical and electron microscopy, and the mechanical properties are discussed in relation to the nanostructures.
\end{abstract}

Keywords: polymer blends, nanostructure, epoxy, block copolymer, mechanical properties

\section{Introduction}

Epoxy thermosets are applied as structural materials and adhesives in many industries, such as aerospace, automotive, and electronics, due to their excellent mechanical properties and heat/solvent resistance. In the applications, polymer blends have been studied to toughen the epoxy thermosets [1-14]. Among various toughening modifiers, block copolymers (BCPs) consisting of chemically distinct block chains have attracted attention in order to give nanostructured epoxy blends [15-40].

After the finding of the nanostructured epoxy blends with amphiphilic BCPs $[15,16]$, many BCPs were synthesized to study the nanostructures and the mechanical properties of the cured blends. Dean et al. [21] reported that methylenedianiline-cured DGEBA/ poly(ethylene oxide)- $b$-poly(butadiene) (PEO- $b$-PB) block copolymer blends showed a phase transition from spherical micelles to branched cylindrical micelles and finally to vesicles, as the volume fraction of the epoxy-miscible PEO block decreased.

Ritzenthaler and coworkers [23, 24] studied epoxy/ $\mathrm{ABC}$ triblock copolymer blends. Raspberry-like nanostructures were identified in polystyrene- $b$ polybutadiene- $b$-poly(methyl methacrylate) triblock polymer (PS- $b$-PB- $b$-PMMA)/DGEBA blends cured

\footnotetext{
${ }^{*}$ Corresponding author, e-mail: kishi@eng.u-hyogo.ac.jp C) BME-PT
} 
with 4,4'-methylene-bis-(3-chloro 2,6-diethyl-aniline) (MCDEA). Serrano et al. [29] prepared nanostructured epoxy blends with polystyrene- $b$-polybutadiene (PS- $b$-PB) diblock copolymers. The MCDEA-cured DGEBA/PS- $b$-PB diblock copolymer blends showed worm-like micelles and hexagonally-packed cylindrical micelles, which were dependent on the amount of BCPs and the degree of epoxidation in the polybutadiene block.

Meng and coworkers [30,31] and Yu and coworkers $[32,33]$ showed that nanostructures of BCP with poly( $\varepsilon$-caprolactone) block/epoxy blends were generated via reaction-induced phase separation. The formation of nanostructures is due to phase separation of the thermoset-phobic blocks of the BCPs from the matrix during the curing process [33].

Blanco et al. [34] clarified that DGEBA/polystyrene$b$-poly(methyl methacrylate) (PS- $b$-PMMA) blends showed self-assembled nanostructures with PS micelles. Romeo et al. [35] reported that the cure cycle determined the types of nanostructures for a DGEBA/ PS- $b$-PMMA blend in which the nanostructures were also generated via reaction-induced phase separation. Cano et al. [36] studied the quantitative nanomechanical properties of MCDEA-cured DGEBA/ PS- $b$-PMMA blends using atomic force microscopy. In terms of the toughening effect, Dean et al. [21] studied aromatic amine-cured DGEBA/poly(ethylene oxide)- $b$-poly(ethylene-alt-propylene) (PEO- $b$-PEP) diblock copolymer blends. The blends showed spherical micelles, wormlike micelles, and vesicles, depending on the ratio of PEO block in the BCP. In the report, the blends with vesicles showed the highest fracture toughness (critical strain energy release rate, $G_{\mathrm{IC}}: 540 \mathrm{~J} / \mathrm{m}^{2}$ ) of the three types of nanostructures. On the other hand, Wu et al. [22] reported that PNcured DGEBA/poly(n-butylene oxide)- $b$-poly(ethylene oxide) (PBO- $b$-PEO) diblock copolymer blends with various nanostructures by changing the composition of the BCPs. The $G_{\text {IC }}$ of the blend with wormlike nanostructures reached $1560 \mathrm{~J} / \mathrm{m}^{2}$, which was higher than the $G_{\mathrm{IC}}$ of the blends with spherical micelles $\left(748 \mathrm{~J} / \mathrm{m}^{2}\right)$, vesicles $\left(587 \mathrm{~J} / \mathrm{m}^{2}\right)$, and the neat epoxy $\left(83 \mathrm{~J} / \mathrm{m}^{2}\right)$.

Serrano et al. [29] reported the $G_{\mathrm{IC}}$ for MCDEAcured DGEBA/PS- $b$-PB diblock copolymer blends with hexagonally-packed cylinders to be approximately $500 \mathrm{~J} / \mathrm{m}^{2}$, which was double that for the corresponding unmodified epoxy resin.
In our previous publications [37-39], poly(methyl methacrylate)- $b$-poly(n-butyl acrylate)- $b$-poly(methyl methacrylate) (PMMA- $b$-PnBA- $b$-PMMA) triblock copolymers (acrylic BCPs) were blended with DGEBA using a wide range of curing agents. Among several cured blends, phenol novolac (PN)-cured DGEBA/acrylic BCP blends gave nanostructures. The miscibility between the PMMA blocks of the BCPs and the PN-cured DGEBA was a key factor in the formation of nanostructures in these blends [37, 39]. Several nanostructures, such as spheres, cylinders (hexagonally-packed or randomly-dispersed), and curved lamellae were formed in the cured blends $[37,38]$, which were controlled according to the molecular weight of the immiscible PnBA-block chain and the ratio of PnBA in the blends [38, 39]. Small angle X-ray scattering analyses indicated that the seeds of the nanostructures were formed via a selfassembly mechanism rather than via reaction-induced phase separation [38]. The $G_{\mathrm{IC}}$ for a PN-cured DGEBA $/ 20$ wt $\%$ PMMA- $b$-PnBA- $b$-PMMA blend having random cylindrical nanostructure was $2530 \mathrm{~J} / \mathrm{m}^{2}$, which was more than twenty times that for the unmodified epoxy thermoset [37].

Thompson et al. [41] controlled the nanostructures of DGEBA $/ 5 \mathrm{wt} \%$ PEO- $b$-PEP blends by changing both the PEO- $b$-PEP composition and the molecular weight between cross-links $\left(M_{\mathrm{c}}\right)$ of the epoxy matrices [41]. The fracture toughness increased as the $M_{\mathrm{c}}$ of the DGEBA/PEO- $b$-PEP blends increased. At an epoxy $M_{\mathrm{c}}$ value of $2900 \mathrm{~g} / \mathrm{mol}$, the $G_{\mathrm{IC}}$ reached $2700 \mathrm{~J} / \mathrm{m}^{2}$. When $M_{\mathrm{c}}$ was changed, the plastic deformation ability of the matrix was simultaneously changed; therefore, it was difficult to simply extract the relationship between the phase structures and the mechanical properties.

Liu et al. [42] discussed toughening mechanisms for DGEBA/PEO- $b$-PEP blends with self-assembled wormlike micelles in comparison with spherical micelles. DGEBA $/ 5 \mathrm{wt} \%$ PEO- $b$-PEP blends were prepared with various weight fractions of the PEO block in the BCP to control the nanostructures of the blends, while $M_{\mathrm{c}}$ for the epoxy matrices was maintained at $600 \mathrm{~g} / \mathrm{mol}$. Elongated cylindrical wormlike micelles resulted in an improvement of toughness of over $100 \%$ that of the pure epoxy. The toughening mechanisms were concluded to be a combination of crack tip blunting, cavitation, particle debonding, limited shear yielding, and crack bridging [42]. 
Overall, various nanostructures have been reported using many types of epoxy/BCP blends. In these studies, different types of nanostructures were formed by changing the basic chemical structures of the BCPs, the molecular weight of the block chains in the $\mathrm{BCPs}$, the composition of the BCPs, and the $\mathrm{BCP}$ content in the polymer blends. Therefore, it has been difficult to make precise comparisons and discuss the relation between the several phase structures and the mechanical properties as a direct effect of the nanostructures. To the best of our knowledge, no report was published in the literature that discusses the mechanical properties in relation to the nanostructures, while maintaining consistent chemical structures and the contents of the $\mathrm{BCP}$, and $M_{\mathrm{c}}$ values of the epoxy matrices in the epoxy/BCP blends. This issue remains important with respect to both scientific and industrial viewpoints. In our previous publication, several nanostructured epoxy/BCP blends were formulated, and the same nanostructure could be controlled within a relatively wide range of $\mathrm{BCP}$ content [38]. Although the nanostructures were altered by changing the $\mathrm{BCP}$ composition as an actual procedure, each nanostructure type (spherical-micelle, random cylindrical-micelle, and curved lamellar micelle) could be fixed within a wide range of the BCP amount. Therefore, the effect of the nanostructures on the mechanical properties of the blends can be discussed with respect to the same corresponding rubber content within the experimental range.

The objective of the current study is to examine the nanostructures of epoxy/BCP blends both two dimensionally and three dimensionally using electron microscopy, and discuss the relation with the mechanical properties, especially the fracture toughness and modulus of elasticity.

\section{Experimental procedure}

\subsection{Materials}

The epoxy thermoset used in this study was DGEBA (jER828, Mitsubishi Chemical Co. Ltd., Japan, epoxy equivalent weight: $189 \mathrm{~g} / \mathrm{eq}$.). PN; (hydroxyl group equivalent weight: 105 g/eq., Sumitomo Bakelite Co., Ltd., Japan) was utilized as the curing agent. Triphenylphosphine (TPP; Tokyo Chemical Industry Co. Ltd., Japan) was applied as a catalyst with the PN. Three types of PMMA- $b$-PnBA- $b$-PMMA triblock copolymers (acrylic BCPs) were applied as modifiers for the epoxy blends. The chemical structure of the acrylic BCPs is shown in Figure 1. The molecular weight of the acrylic BCPs and the composition (ratio of PnBA in the acrylic BCPs) were systematically controlled, as shown in Table 1 . The PnBA block chain is immiscible and the PMMA block chain is miscible with the TPP catalyzed PN-cured DGEBA matrix polymer [37-39].<smiles>CC(CC(O)COc1ccc(C(C)(C)c2ccc(OCC3CO3)cc2)cc1)c1ccc(OCC(C)(C)c2ccc(OCC3CO3)cc2)cc1</smiles>

Diglycidyl ether of bisphenol-A (DGEBA)
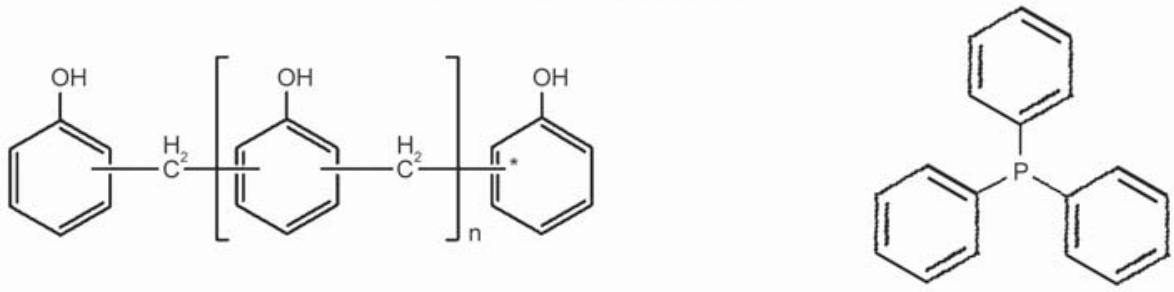

Phenol novolac (PN)

Tri phenyl phosphine (TPP)

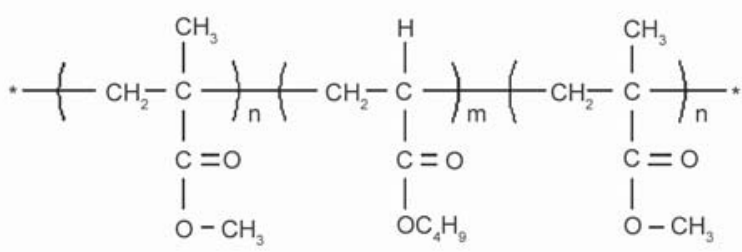

PMMA-b-PnBA- $b-P M M A$ triblock copolymers

Figure 1. Chemical structure of epoxy thermoset, curing agent, and PMMA- $b$-PnBA- $b$-PMMA triblock copolymer (BCP) 
Table 1. Weight-average molecular mass $\left(M_{\mathrm{w}}\right)$, PnBA content and polydispersity of PMMA- $b$-PnBA- $b$-PMMA triblock copolymers (BCP)

\begin{tabular}{|c|c|c|c|}
\hline No. of BCP & $\begin{array}{c}\text { Molecular weight } \\
\boldsymbol{M}_{\mathbf{w}}\end{array}$ & $\begin{array}{c}\text { PnBA in BCP } \\
{[\mathbf{w t} \% \mathbf{0}}\end{array}$ & $\boldsymbol{M}_{\mathbf{w}} / \boldsymbol{M}_{\mathbf{n}}$ \\
\hline BCP50-6 & 64000 & 50 & 1.19 \\
\hline BCP68-6 & 60000 & 68 & 1.25 \\
\hline BCP77-7 & 72000 & 77 & 1.19 \\
\hline
\end{tabular}

\subsection{Size exclusion chromatography}

The molecular weight distributions of the BCPs were determined using size exclusion chromatography (SEC; PU-2080 HPLC system, Jasco, with JascoBorwin-GPC software), which was equipped with two connected Shodex LF-804 columns. Tetrahydrofuran (THF) was used as the solvent. The average molecular weights were calibrated using mono-dispersed polystyrene standards.

\subsection{Preparation of cured thermosets}

The DGEBA/acrylic BCP systems were cured using the following procedure. First, the $\mathrm{BCP}$ was mixed with DGEBA at room temperature. The mixture was heated in an oil bath at $200{ }^{\circ} \mathrm{C}$ for 30 min with stirring to dissolve the $\mathrm{BCP}$ in the DGEBA. After the mixture was cooled to below $100^{\circ} \mathrm{C}$, stoichiometric quantities of $\mathrm{PN}$ and a small amount [0.5 parts per hundred parts of resin (DGEBA +PN): phr] of TPP were added to the mixture and degassed. The mixture was cast into a pre-treated mold with a release agent. The mixture was cured at $120^{\circ} \mathrm{C}$ for $2 \mathrm{~h}$, followed by a post-cure at $150^{\circ} \mathrm{C}$ for $2 \mathrm{~h}$. After this procedure, the oven was switched off and the cured polymers were allowed to cool slowly to room temperature.

\subsection{Microscopy observation}

\subsubsection{Transmission electron microscopy (TEM)}

Thin sections of the cured polymers were cryomicrotomed at $-80^{\circ} \mathrm{C}$. The setting thickness was 40 $50 \mathrm{~nm}$. Microtomed thin sections of the cured polymers were stained with $\mathrm{RuO}_{4}$ vapor and observed using transmission electron microscopy (TEM; H-7650, Hitachi, Japan) operated at an acceleration voltage of $100 \mathrm{kV}$. Three-dimensional (3D) images were constructed using IMOD 3.11.5 software (Mercury Computer Systems, Amira).

\subsubsection{Scanning electron microscopy (SEM)}

The fracture surfaces of the cured resins were observed using scanning electron microscopy (SEM; VE9800, Keyence, Japan). The samples were mounted on brass stubs and coated with a thin layer of gold using an ion sputter coater (JFC-1100E, Jeol, Japan).

\subsubsection{Optical microscopy (OM)}

Plastic deformation of the specimens after the fracture toughness evaluation was examined using a petrographic sectioning technique and an optical microscope. The mid-planes in the thickness direction of the fractured specimens were cut using a low-speed diamond saw (Minitom, Marumoto-Struers, Japan). One half of the specimen was mounted onto an optical microscope slide. The mounted specimens were polished petrographically into $100 \mu \mathrm{m}$ thick crosssections. The shear deformation bands in the thin sections were observed under cross-polarized transmitted light using an optical microscope (Eclipse E600W, Nikon, Japan).

\subsection{Fracture toughness of cured thermosets}

Fracture toughness (critical stress intensity factor: $K_{\mathrm{IC}}$ ) of the cured epoxy resins was measured by the single edge notched three-point bending (SEN-3PB) method according to ASTM D 5045. The dimensions of the specimens were $55 \mathrm{~mm}$ long $\times 12 \mathrm{~mm}$ wide $\times 6 \mathrm{~mm}$ thick. The span length for the bending test was $48 \mathrm{~mm}$. The initial crack length was within the range of $6.1 \pm 0.5 \mathrm{~mm}$ to satisfy the geometric requirement. The three-point bending tests were performed with a testing rate of $10 \mathrm{~mm} / \mathrm{min}$ at $23^{\circ} \mathrm{C}$ using a universal testing machine (Autograph AGS-J 10 kN, Shimadzu, Japan). The critical strain energy release rate $\left(G_{\mathrm{IC}}\right)$ was then calculated from the $K_{\mathrm{IC}}$, modulus of elasticity and Poisson's ratio for the specimen. The detail of the test can be referred in the previous publication [37].

\subsection{Flexural modulus of elasticity $(E)$ of cured thermosets}

Three-point bending tests were conducted for specimens with a size of $50 \times 10 \times 2 \mathrm{~mm}^{3}$ using a universal testing machine (Autograph AGS-J 10 kN, Shimadzu, Japan). The span was $24 \mathrm{~mm}$ and the crosshead speed was $5 \mathrm{~mm} / \mathrm{min}$.

\subsection{Dynamic viscoelastic analysis (DMA) of the cured thermosets}

The temperature dependencies of the viscoelastic properties (storage modulus: $E^{\prime}$ and loss tangent: $\tan \delta$ ) of the cured resins were evaluated by dynamic mechanical analysis in tensile mode (DMA: DMS6100, Seiko Instruments, Inc., Japan). The dynamic 
frequency was $1 \mathrm{~Hz}$ and the amplitude was $10 \mu \mathrm{m}$. The samples were tested over a temperature range between -100 and $250^{\circ} \mathrm{C}$ in the heating rate of $2{ }^{\circ} \mathrm{C} /$ minute. The detail of the test can be referred in the previous publication [37].

\section{Results and discussion}

\subsection{D nanostructures of cured epoxy/PMMA-b-PnBA- $b$-PMMA triblock copolymers}

The cured epoxy/BCP blends were the same materials as those in our previous publication [38]. Figure 2 (10 wt $\%$ BCP in the blends) and Figure 3 (20 wt $\%$ $\mathrm{BCP}$ in the blends) show the two-dimensional nanostructures of the cured blends, observed using TEM. The relatively dark phases consisted of PnBA stained with $\mathrm{RuO}_{4}$, and the bright matrix consisted mainly of the epoxy thermoset, as confirmed in our previous publications [37-39].

The cured DGEBA/BCP50-6 blends showed spherical micelles in both the 10 and $20 \mathrm{wt} \% \mathrm{BCP}$ blends. The spherical PnBA micelles were dispersed in the epoxy matrices. The cured DGEBA/BCP68-6 blends showed randomly directed cylindrical micelles in both the 10 and $20 \mathrm{wt} \%$ BCP blends. The cured DGEBA/ BCP77-7 blends had curved lamella structures in both the 10 and $20 \mathrm{wt} \% \mathrm{BCP}$ blends. Thus, in the experimental range of the blend compositions, the same type of nanostructure was maintained in each epoxy/ $\mathrm{BCP}$ combination.

The continuity of the cylindrical micelle and the curved lamella nanostructures required clarification. Therefore, 3D TEM was applied to observe these two nanostructure types. Figure 4 shows a 3D image of the $20 \mathrm{wt} \%$ BCP68-6/epoxy blend. The white cylindrical micelles were dispersed randomly in any direction. Many ends of the cylinders were found within the observation area $(890 \mathrm{~nm} \times 890 \mathrm{~nm} \times 183 \mathrm{~nm})$ of the microtomed sample. The 3D image clearly clarifies that the cylindrical micelles are dispersed discontinuously in the epoxy matrix. Figure 5 shows a 3D image of the $20 \mathrm{wt} \%$ BCP77-7/epoxy blend. Here, the observation area $(2900 \mathrm{~nm} \times 2900 \mathrm{~nm} \times$ $230 \mathrm{~nm}$ ) was wider than the blend with cylindrical micelles. The curved lamellae (white phase in Figure 5) were continuous throughout the entire 3D observation area. In addition, the epoxy matrix (black phase) in Figure 5 were also continuous in 3 dimensionally.

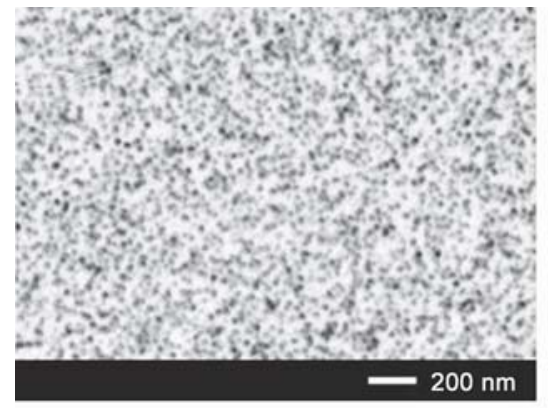

a)

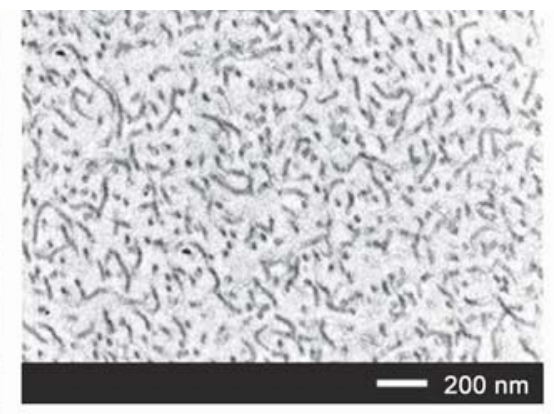

b)

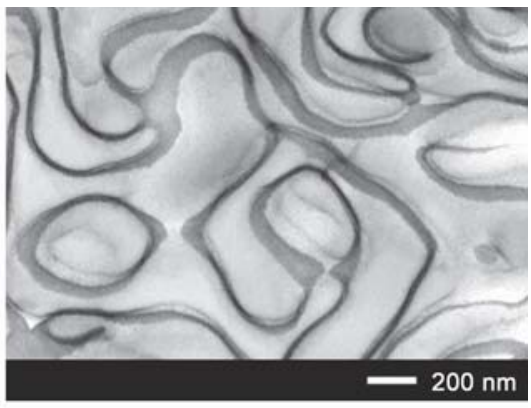

c)

Figure 2. Effect of PnBA content in the acrylic BCPs on the phase structures of PN-cured DGEBA/10 wt $\%$ acrylic BCP blends [38]: (a) DGEBA/BCP50-6 (PnBA content in the BCP: $50 \mathrm{wt} \%$ ), (b) DGEBA/BCP68-6 (PnBA content in the BCP: $68 \mathrm{wt} \%$ ), (c) DGEBA/BCP77-7 (PnBA content in the BCP: $77 \mathrm{wt} \%$ )

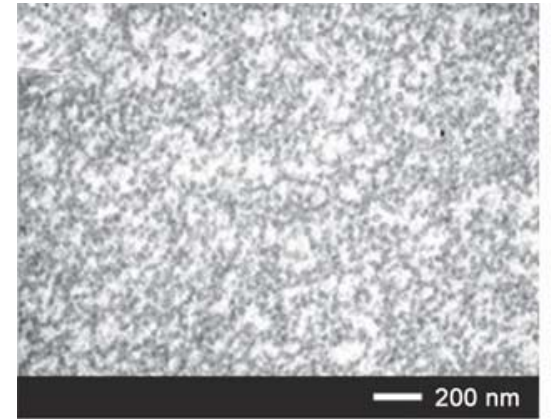

a)

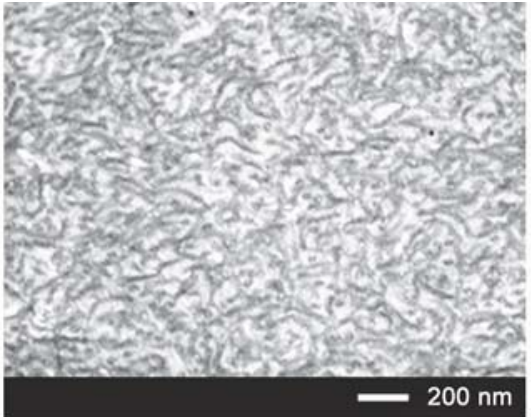

b)

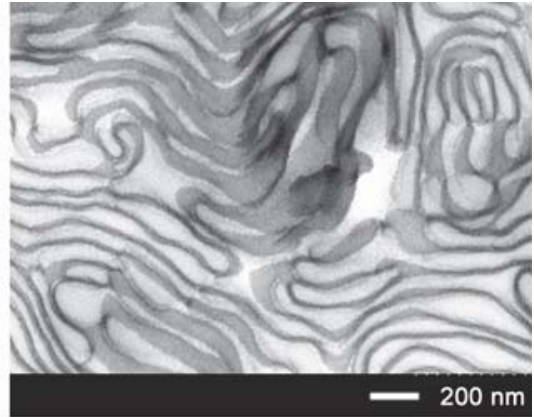

Figure 3. Effect of PnBA content in the acrylic BCPs on the phase structures of PN-cured DGEBA/20 wt $\%$ acrylic BCP blends [38]: (a) DGEBA/BCP50-6 (PnBA content in the BCP: $50 \mathrm{wt} \%$ ), (b) DGEBA/BCP68-6 (PnBA content in the BCP: $68 \mathrm{wt} \%$ ), (c) DGEBA/BCP77-7 (PnBA content in the BCP: $77 \mathrm{wt} \%$ ) 
Therefore, the curved lamellae morphology can be defined as 'co-continuous' nanostructure.

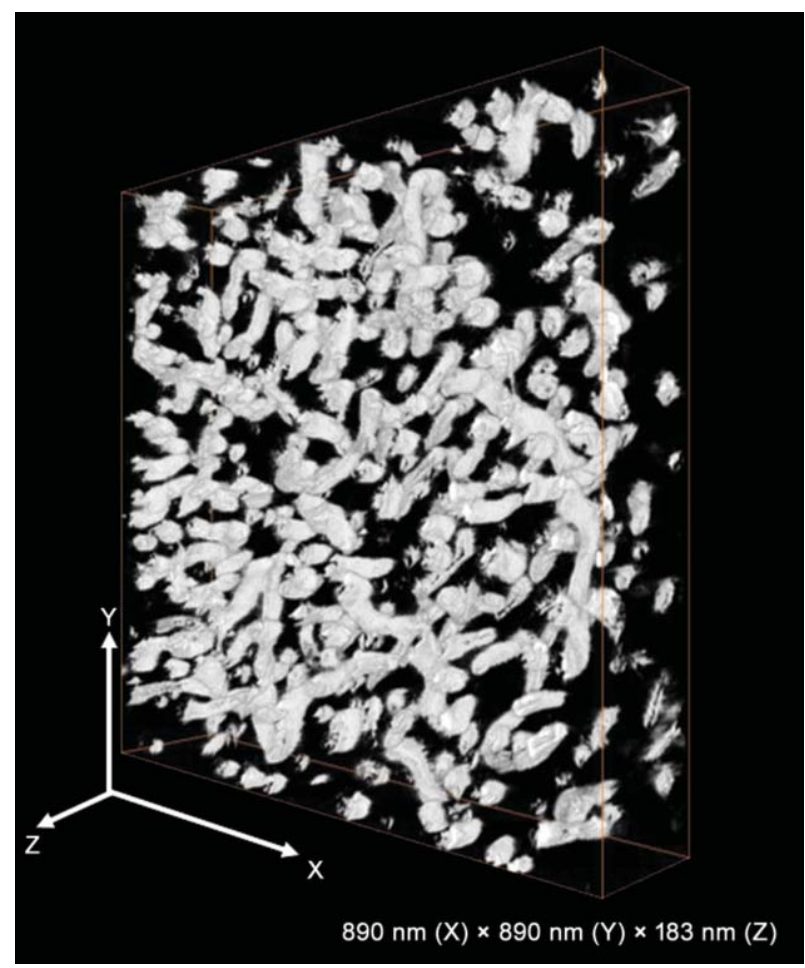

Figure 4. 3D structure of PN-cured DGEBA/20 wt $\%$ BCP68-6 blend. Note the random cylindrical micelles were discontinuous in the epoxy matrix.

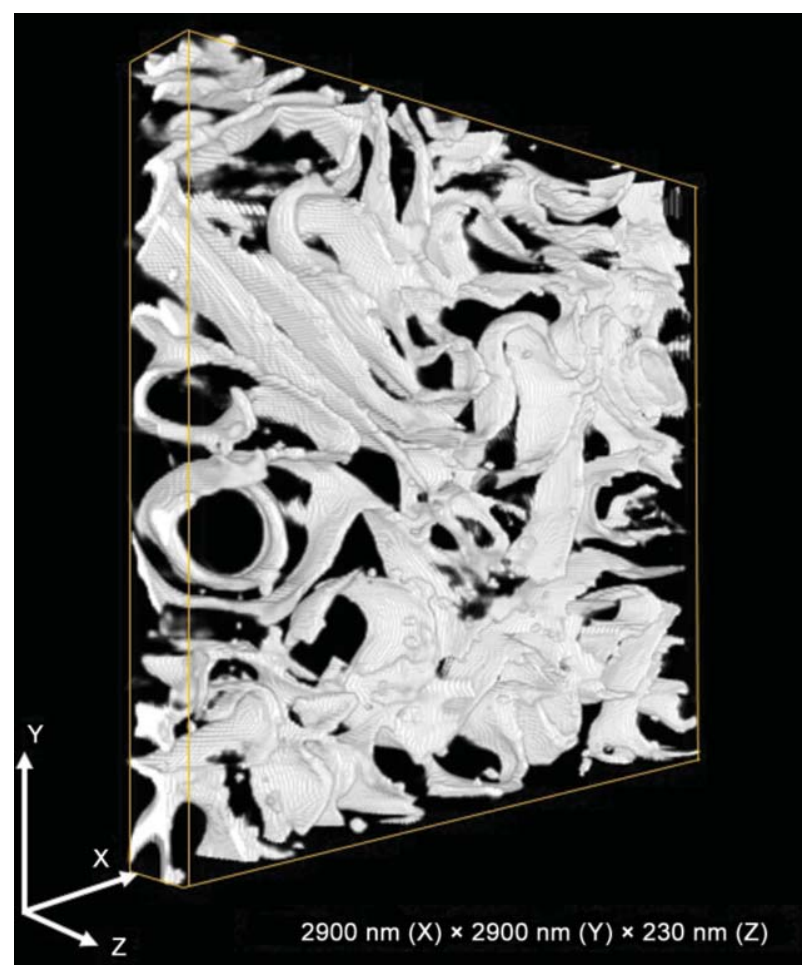

Figure 5. 3D structure of PN-cured DGEBA/20 wt $\%$ BCP77-7 blend. Note the curved lamellae morphology was three-dimensionally co-continuous nanostructure.

\subsection{Mechanical properties of cured epoxy/PMMA-b-PnBA- $b$-PMMA triblock copolymers and relation to the nanostructures}

The temperature dependencies of dynamic viscoelastic properties of the three types of epoxy/ $20 \mathrm{wt} \%$ BCP blends were shown in Figure 6. All three blends indicated two glass transition temperatures $\left(T_{\mathrm{g}}\right)$ with the change of the storage modulus $\left(E^{\prime}\right)$ and the peaks of loss tangent $(\tan \delta)$. The first $T_{\mathrm{g}}$ was around $-45^{\circ} \mathrm{C}$ corresponding to the $T_{\mathrm{g}}$ of PnBA phase. Especially, prominent decrease of $E^{\prime}$ was seen at this temperature in case of epoxy $/ 20 \mathrm{wt} \% \mathrm{BCP} 77-7$ blend, compared to both $20 \mathrm{wt} \%$ BCP50- 6 blend and $20 \mathrm{wt} \%$ BCP $68-6$ blend. This also suggests the difference of the continuity of the PnBA phase in the three blends, that is, the epoxy/BCP77-7 blend has continuous PnBA phases. The second $T_{\mathrm{g}} \mathrm{s}$ were around $130^{\circ} \mathrm{C}$ corresponding to the $T_{\mathrm{g}}$ of $\mathrm{PN}$-cured DGEBA in all three types of epoxy/BCP blends. Almost the same second $T_{\mathrm{g}}$ s suggest the stoichiometric reaction occurred in these epoxy/BCP blends, irrespective of the difference of the nanostructures.

Then, the mechanical properties, specifically the $G_{\text {IC }}$ and $E$, of the epoxy/BCP blends were evaluated to find the relation with the three nanostructure types. Figure 7 shows the relation of $G_{\mathrm{IC}}$ with respect to the nanostructures of the blends. Figure 7 a shows $G_{\mathrm{IC}}$ for the blends as a function of the BCP content. The toughness increased with the BCP content for all of the nanostructures. Here, each BCP had a different

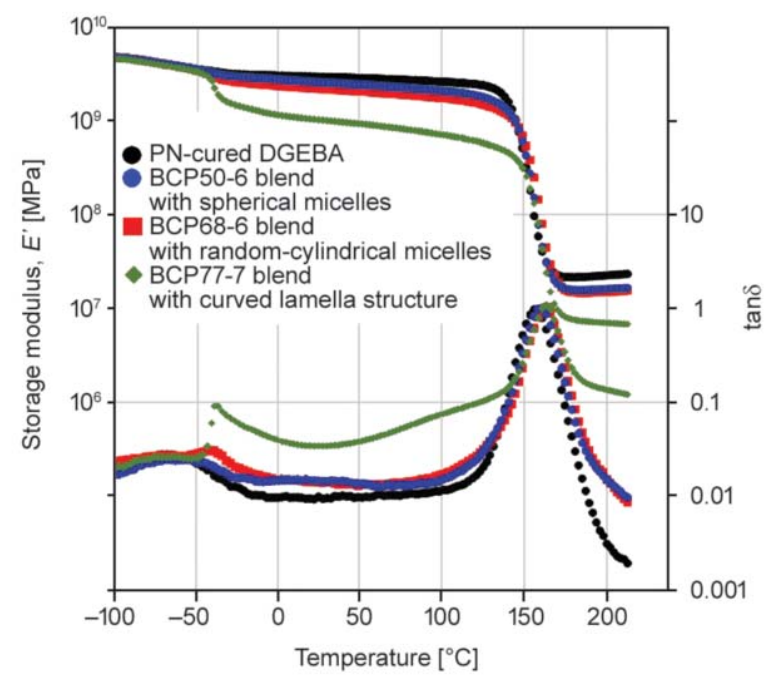

Figure 6. Dynamic mechanical analyses of PN-cured DGEBA $/ 20 \mathrm{wt} \%$ BCP blends and the pure PNcured DGEBA 


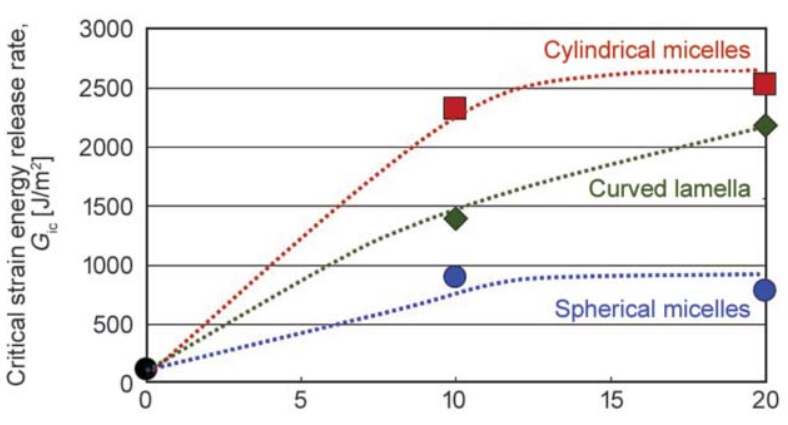

a)

Block copolymer content in cured blend [wt $\%]$

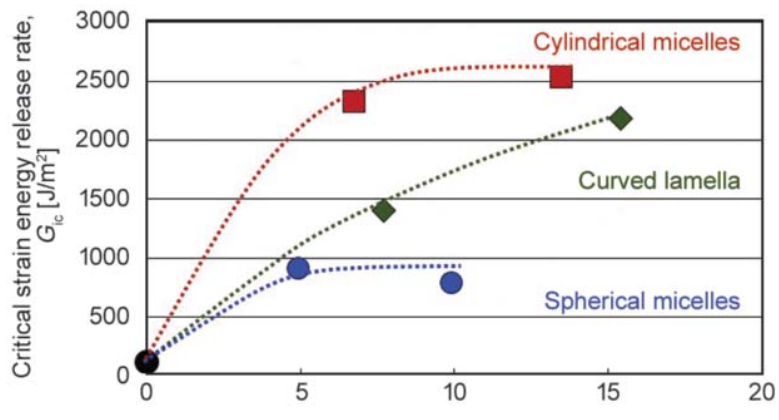

b)

PnBA content in cured blend [wt \%]

Figure 7. Effect of nanostructure on the fracture toughness of PN-cured DGEBA/acrylic BCP blends: (a) dependence of $G_{\text {IC }}$ on BCP content in the cured blends, (b) dependence of $G_{\mathrm{IC}}$ on PnBA content in the cured blends

amount of elastomeric component (PnBA) in the composition. Therefore, considering the important role of the elastomeric component on the toughening mechanisms, the BCP content should be converted into the PnBA content in the epoxy/BCP blends, as shown in Figure 7b. Figure 7b clearly indicates that the blends with cylindrical micelles had the highest toughening effect among the 3 types of nanostructures.

Figure 8 shows $E$ for the epoxy/BCP blends in relation to the nanostructures. $E$ decreased with an increase in the $\mathrm{BCP}$ content (Figure 8a), or with an increase in the PnBA content in the blends (Figure $8 \mathrm{~b}$ ). Figure $8 \mathrm{~b}$ shows that the spherical micelles and random-cylindrical micelles gave almost the same line of decrease of $E$ in relation to the PnBA content. In contrast, for the curved lamella structure, a drastic decrease in $E$ occurred with a small addition of PnBA, which is discussed later in section 3.4.

\subsection{Toughening mechanisms for cured epoxy/PMMA-b-PnBA- $b$-PMMA triblock copolymers}

The toughening mechanisms for the cured epoxy/ acrylic $\mathrm{BCP}$ blends were examined in relation to the

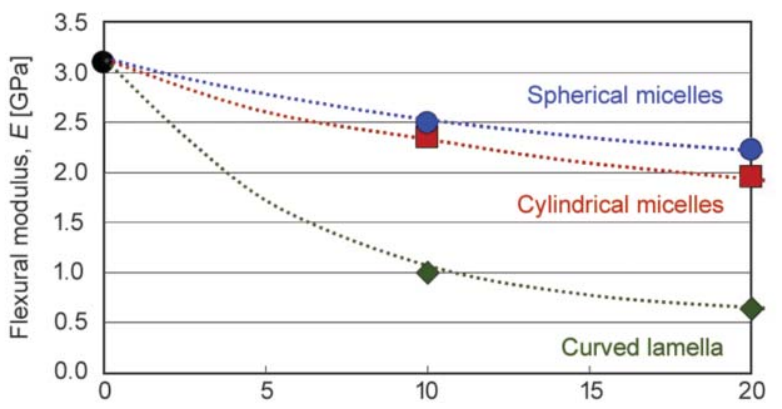

a) Block copolymer content in cured blend [wt\%] nanostructures, using optical and electron microscopy. Macroscopically, the cured blends with both cylindrical micelles and the curved lamella structure showed stress-whitening on the fracture surfaces after $G_{\mathrm{IC}}$ evaluation. In contrast, almost no stress-whitening was observed on the fracture surfaces of the blends with spherical micelles.

Figure 9 shows SEM images of the fracture surfaces of the three types of nanostructures in the cured blends. Although many cavities were observed on all the fracture surfaces, the shape and sizes were different from each other. Spherical cavities with sizes of tens of nanometers were observed in the blends with spherical micelles (Figure 9a), whereas elongated cavities were observed in the complicated rough surfaces of the blends with cylindrical micelles (Figure 9b). On the other hand, large grooves were observed in the blends with the curved lamella structure, which resulted in the largest roughness on the fracture surfaces among the three types of nanostructured blends (Figure 9c). In addition, plastic deformation of the epoxy matrix around the cavities and the void growth was observed, especially in the blends with both cylindrical micelles and the curved lamella structure (Figure 9b, 9c).

Figure 8. Effect of nanostructure on $E$ for PN-cured DGEBA/acrylic BCP blends: (a) dependence of $E$ on BCP content in the cured blends, (b) dependence of $E$ on PnBA content in the cured blends 


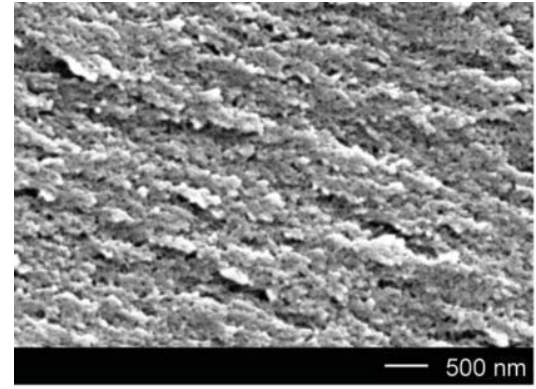

a)

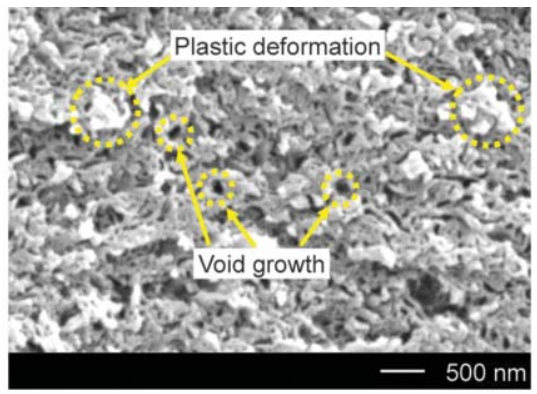

b)

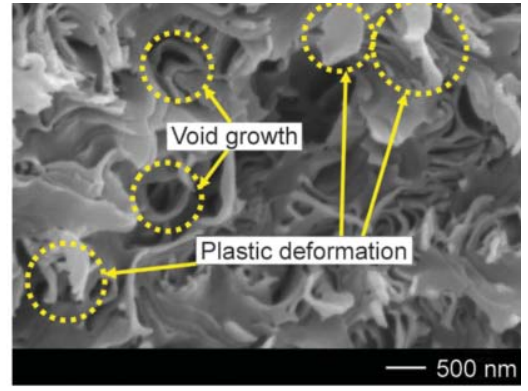

c)

Figure 9. Fracture surfaces of PN-cured DGEBA/acrylic BCP blends: (a) DGEBA/20 wt $\%$ BCP50-6 blend with spherical micelles, (b) DGEBA/20 wt\% BCP68-6 blend with random-cylindrical micelles, (c) DGEBA/20 wt\% BCP77-7 blend with curved lamella structure

Elastomer-toughening mechanisms for epoxy blends have been studied by many researchers [1-6]. In several of these publications, the role of the elastomer phases was reported to relieve the constraint effect in front of a crack tip by cavitation of the elastomer particles. It was clarified that the cavitation altered the stress field from tri-axial tension dominance to shear stress dominance, which promoted plastic deformation (formation of shear bands) of the epoxy matrix polymer [3-6].

The PnBA micelles in the present study are the elastomeric phases. The nanocavities on the fracture surfaces were originated from PnBA micelles in the blends. As such, the observed plastic deformation around the nanocavities resulted from yielding and elongation of the epoxy matrix. However, the information obtained from observation of the fracture surfaces was limited, considering the internal deformation and total fracture events of the specimens. Therefore, side-view observations were conducted to examine and compare the extent of plastic deformation that would be generated at the process zone in front of a pre-crack tip in a nanostructured epoxy blend.

Figure 10 was optical microscopy images obtained under both bright-field (Figure 10a-1, 10b-1, 10c-1) and cross-polarized light (Figure 10a-2, 10b-2, $10 \mathrm{c}-2)$. The same position in each sample was photographed under both bright-field and cross-polarized light, therefore one can judge where birefringence was from. The blends with spherical micelles showed a birefringent zone in the crack tip region under cross-polarized light (Figure 10a-2). However, the size of the birefringent zone, which indicates the area of shear plastic deformation, was very small and localized. On the other hand, in the blends with random-cylindrical micelles, a considerable amount of birefringent zone was spread in the crack tip region
(Figure 10b-2), which indicates that larger and more diffuse plastic deformation occurred in the blends with cylindrical micelles than in the blends with spherical micelles. The amount of plastic deformation of the epoxy matrix would be responsible for the energy absorption, i.e., $G_{\mathrm{IC}}$. In the case of the blends with curved lamella nanostructures, relatively weak birefringence was observed (Figure 10c-2), which suggests that the inner plastic deformation of the blends was weak. In summary, the blends with randomcylindrical micelles showed the largest birefringence among the three nanostructure types, which indicates in which nanostructures the largest plastic deformation would be generated during the fracture process. Figure 11 shows the side-views taken using TEM at the crack tip region of blends with spherical micelles (Figure 11a) and cylindrical micelles (Figure 11b). Both cavitations of elastomeric PnBA micelles and plastic deformation regions were observed in both blends with spherical micelles and with cylindrical micelles. However, it was evident that PnBA micelles that did not undergo cavitation were also present in the same regions. Moreover, TEM observations of the fractured specimens were conducted from the surface region toward the depth direction to clarify the extent of the cavitation and deformation area. For the epoxy/BCP blends with spherical micelles, the depth of the area that underwent cavitation of the spherical micelles was a maximum of approximately $7 \mu \mathrm{m}$, although this was dependent on the distance from the crack-tip. On the other hand, in case of the blends with cylindrical micelles, the depth of the area that underwent cavitation was greater than $16 \mu \mathrm{m}$. The large area of cavitation-induced plastic deformation in the epoxy matrix with cylindrical micelles would be responsible for the large energy absorption, and thus the high fracture toughness $\left(G_{\text {IC }}\right)$. 


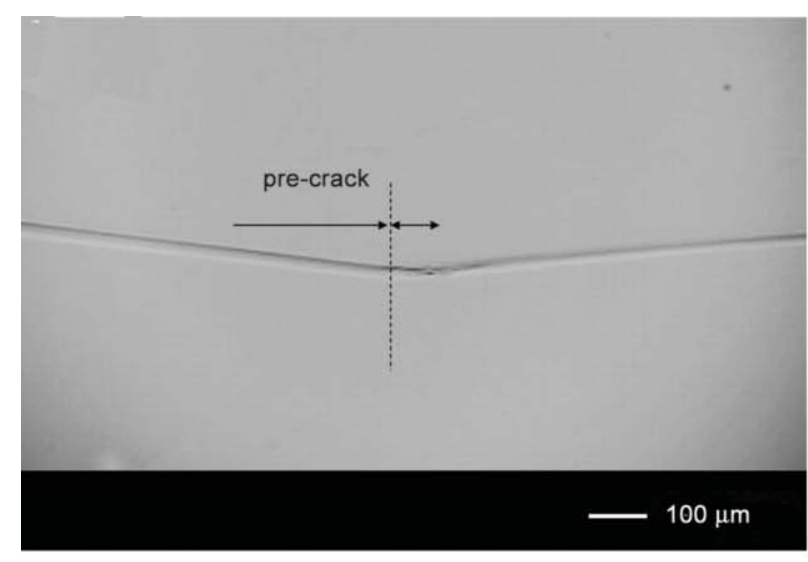

a-1)

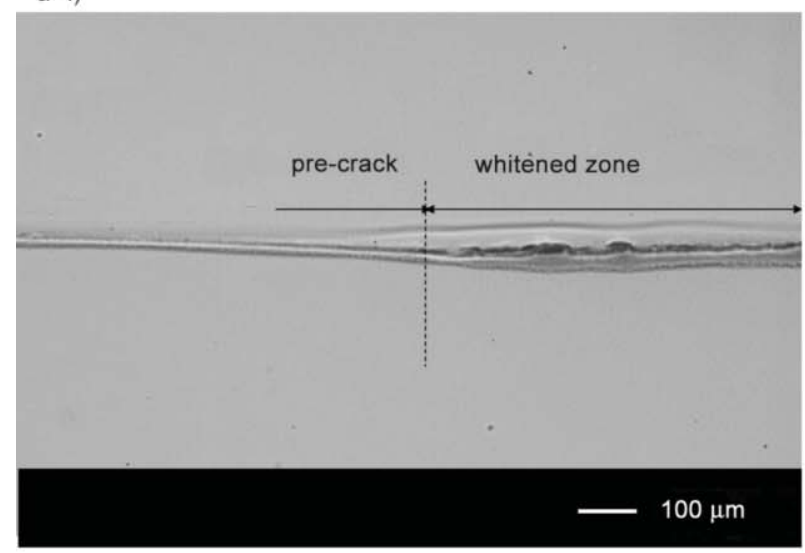

b-1)

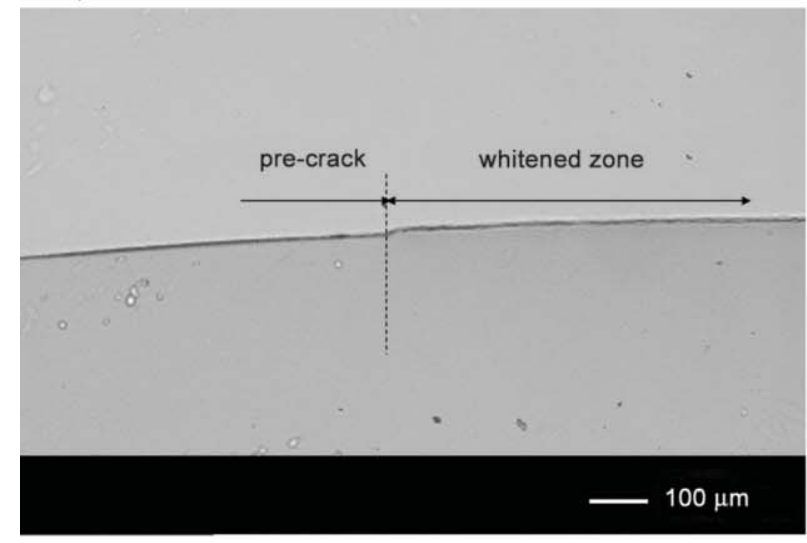

c-1)

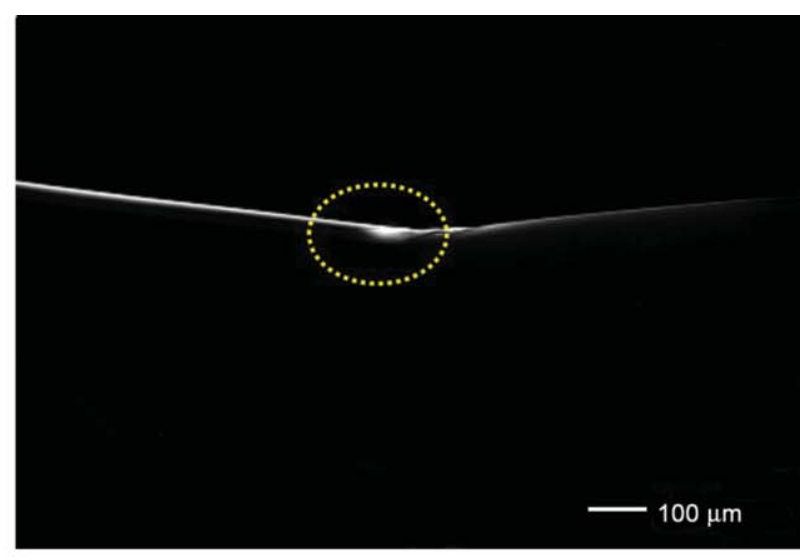

a-2)

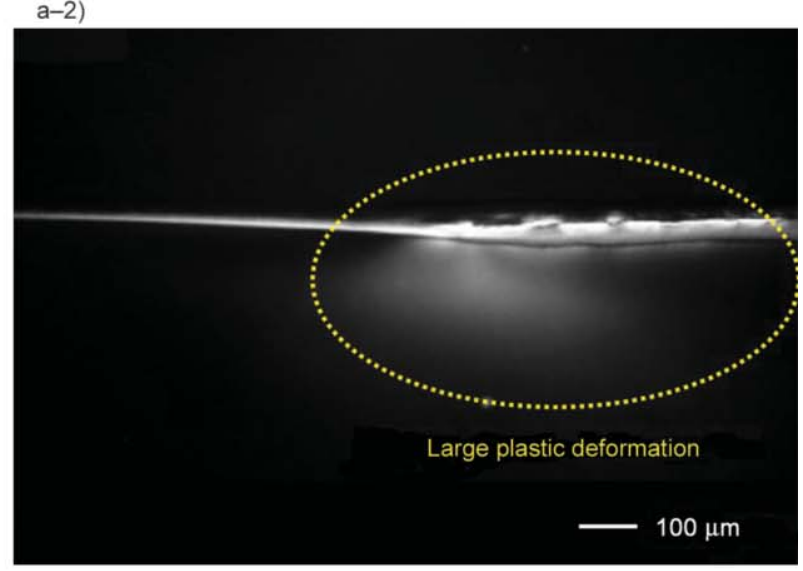

b-2)

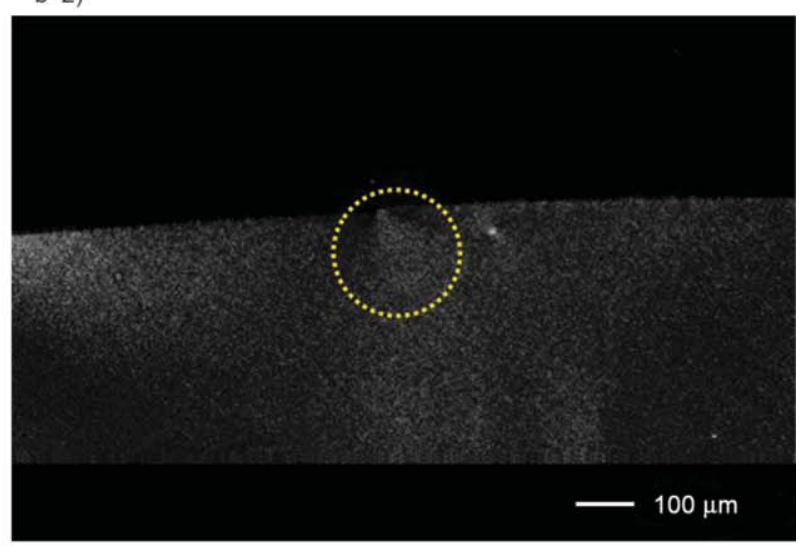

$c-2)$

Figure 10. Side-views of PN-cured DGEBA/acrylic BCP blends, using optical microscopy: 1) bright-field, and 2) under cross-polarized light; (a) DGEBA/20 wt \% BCP50-6 blend with spherical micelles, (b) DGEBA/20 wt \% BCP68-6 blend with random-cylindrical micelles, (c) DGEBA/20 wt\% BCP77-7 blend with curved lamella structure

TEM observations at the crack-tip region of the DGEBA/BCP blend with cylindrical micelles were also conducted on a specimen before application of a load. Figure 12 shows the presence of crack bridging by PnBA cylindrical micelles.

As described in the Introduction, Liu et al. [42] pointed out that the toughening mechanisms of 1,1,1-tris (4-hydroxyphenyl) ethane-cured DGEBA/PEO-PEP blends with wormlike (cylindrical) micelles were a combination of crack tip blunting, cavitation, particle debonding, limited shear yielding, and crack bridging. In the PN-cured DGEBA/acrylic BCP blends of our present study, cavitation of the elastomer nanophase, shear yielding (plastic deformation) of the epoxy matrix, crack tip blunting, and crack bridging by the cylindrical micelles were also observed. However, particle debonding was not observed. The miscibility of the epoxyphilic block of BCP in the epoxy matrix and the molecular weight of the block would be key factors to determine the occurrence of particle 


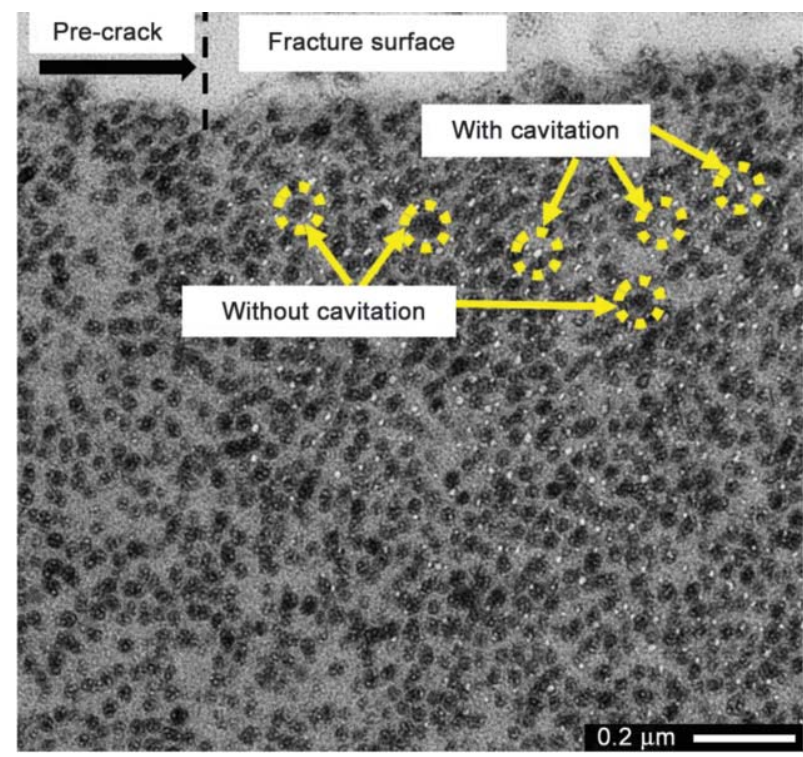

a)

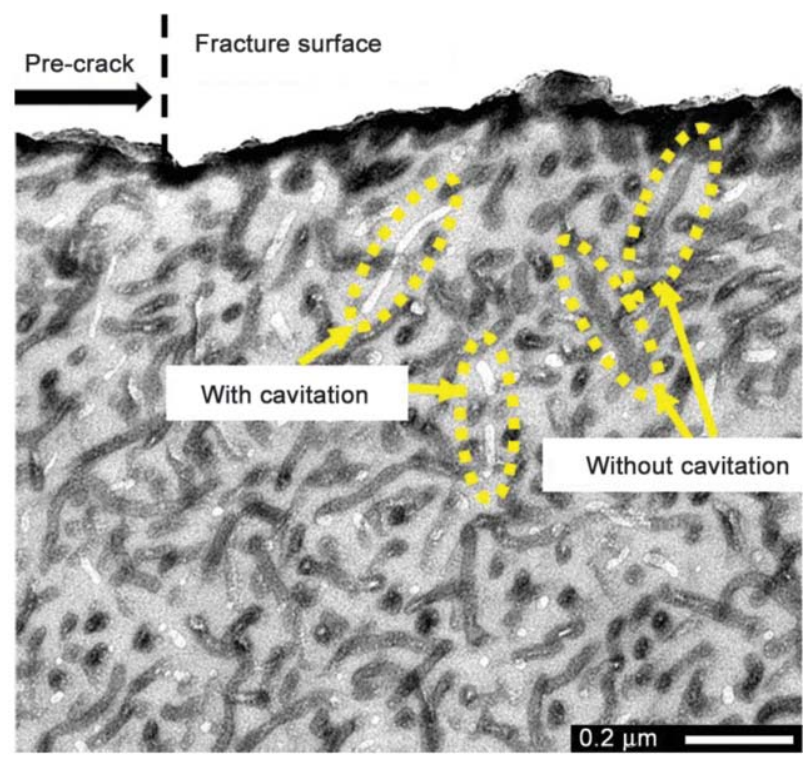

b)

Figure 11. Side views of PN-cured DGEBA/20 wt \% BCP, using TEM: (a) DGEBA/BCP50-6 blend with spherical micelles, (b) DGEBA/BCP68-6 blend with random-cylindrical micelles

debonding. Therefore, the contribution of each mechanism to the toughening effect would be dependent on the individual materials. For the materials in the present work, shear yielding of the epoxy matrix would be the major factor among the several toughening mechanisms, although the precise contribution of each toughening mechanism has not yet been clarified.

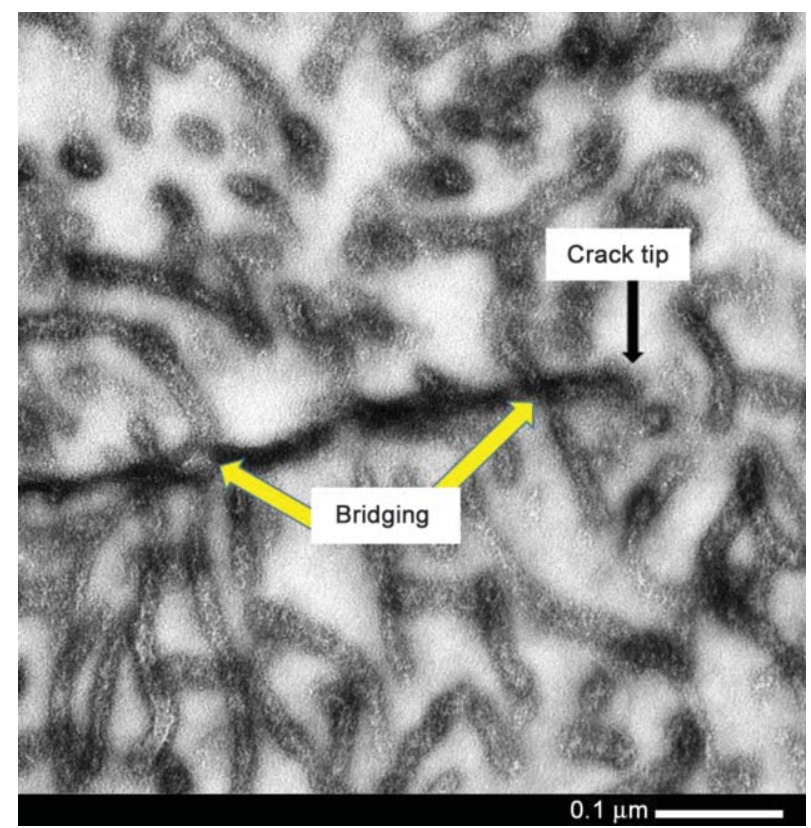

Figure 12. Pre-crack tip region of $\mathrm{PN}$-cured DGEBA $/ 20 \mathrm{wt} \%$ BCP68-6 blend with random-cylindrical micelles, prior to application of a load. Note the presence of crack bridging by PnBA cylindrical micelles.

\subsection{Modulus of elasticity and the relation to the nanostructures of cured epoxy/PMMA- $b$-PnBA- $b$-PMMA triblock copolymers}

Several theoretical models have been examined to predict the elastic moduli of polymer blends since the late 1960s [43-46]. Figure 13 shows theoretically predicted values for the modulus of elasticity, compared with experimental results for the three types of nanostructured blends in Figure $8 b$ as a function of the PnBA content (vol\%) in the epoxy/acrylic

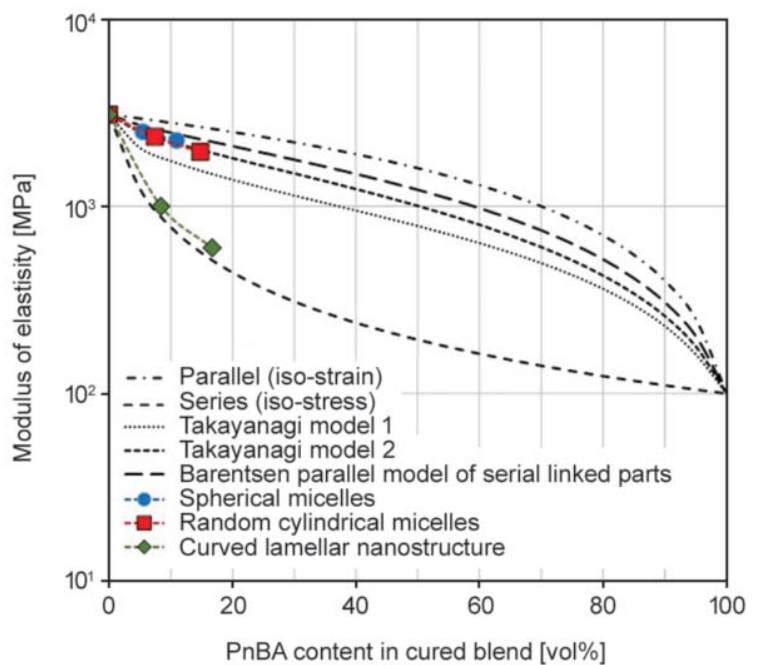

Figure 13. Comparison of the theoretically predicted and the experimental elastic moduli for PN-cured DGEBA/ acrylic $\mathrm{BCP}$ blends with the three types of nanostructures, as a function of the PnBA fraction in the blends 
BCP blends. Classical 2D models, the so-called parallel and series models [43], are indicated as the respective upper and the lower bounds of the theoretically plausible elastic moduli in Figure 13. An isostrain precondition was assumed for the parallel model, and an iso-stress precondition was assumed for the series model. Okamoto and Takayanagi [43] presented two different combinations of the parallel and series models. The predictions from these models are also presented in Figure 13. Barentsen [46] proposed 3D combination models of the parallel and series models. Figure 12 also includes also the prediction from Barentsen's parallel model of serial linked parts for polymer blends. The Okamoto and Takayanagi models and the Barentsen model assumed the morphology of the dispersed domains in the matrix polymer phase. The morphology corresponds with the 3D TEM observations discussed in section 3.1, i.e., the discontinuous micelles consisted of PnBA elastomer dispersed in the epoxy matrix for both the blend with spherical micelles and that with random cylindrical micelles. The experimental results for the elastic moduli of the blends with spherical micelles and random cylindrical micelles examined in this work fell between the prediction of the Okamoto and Takayanagi model and that of the Barentsen model. On the other hand, the experimental data for the blends with the curved lamella structure were close to the line predicted from the classical series model. In other words, the curved lamella nanostructure realized the lowest boundary in the theoretically assumable elastic moduli. This was probably because only the curved lamella structure had continuous elastomer phase in the three types of nanostructured blends. The mechanical properties (i.e., fracture toughness and the modulus of elasticity) of the epoxy/ acrylic BCP blends can now be precisely controlled by control of the nanostructures of the blends.

\section{Conclusions}

The mechanical properties and their relation to the nanostructures of PN-cured DGEBA/PMMA- $b$ PnBA- $b$-PMMA triblock copolymers (acrylic BCPs) were investigated. Several nanostructures, such as spheres, randomly-dispersed cylinders, and curved lamella were observed in the cured epoxy blends using TEM. 3D TEM observation clarified that the spherical micelles and random cylindrical micelles, consisted of epoxy-immiscible PnBA phases, were dispersed discontinuously in the epoxy matrix. In contrast, the curved lamella morphology formed a co-continuous nanostructure, in which both the PnBA phase and epoxy phase formed continuous channels. The highest $G_{\text {IC }}$ was obtained from the randomly-dispersed cylindrical nanostructure blends of the three types of nanostructures having the same PnBA content. The major toughening mechanism was determined to be shear yielding (plastic deformation) of the epoxy matrix after undergoing cavitation of cylindrical micelles consisting of PnBA elastomer. The lowest $E$ was obtained from the curved lamella blends (co-continuous nanostructure). $E$ for the blends could be explained using several theoretical models. $G_{\mathrm{IC}}$ and $E$ for the epoxy/acrylic BCP blends can thus be designed by control of the nanostructures in the blends.

\section{Acknowledgements}

This work was financially supported by a Grant-in Aid for Scientific Research (15H04135) from the Ministry of Education, Culture, Sports, Science and Technology of Japan.

\section{References}

[1] Kinloch A. J., Shaw S. J., Tod D. A., Hunston D. L.: Deformation and fracture behaviour of a rubber-toughened epoxy: 1. Microstructure and fracture studies. Polymer, 24, 1341-1354 (1983). https://doi.org/10.1016/0032-3861(83)90070-8

[2] Yee A. F., Pearson R. E.: Toughening mechanisms in elastomer-modified epoxies. Part 1 Mechanical studies. Journal of Materials Science, 21, 2462-2474 (1986). https://doi.org/10.1007/BF01114293

[3] Pearson R. E., Yee A. F.: Toughening mechanisms in elastomer-modified epoxies. Part 2 Microscopy studies. Journal of Materials Science, 21, 2475-2488 (1986). https://doi.org/10.1007/BF01114294

[4] Pearson R. E., Yee A. F.: Toughening mechanisms in elastomer-modified epoxies. Part 3 The effect of crosslink density. Journal of Materials Science, 24, 25712580 (1989).

https://doi.org/10.1007/BF01174528

[5] Yee A. F., Li D., Li X.: The importance of constraint relief caused by rubber cavitation in the toughening of epoxy. Journal of Materials Science, 28, 6392-6398 (1993).

https://doi.org/10.1007/BF01352202

[6] Kishi H., Shi Y-B., Huang J., Yee A. F.: Ductility and toughenability study of epoxy resins under multiaxial stress states. Journal of Materials Science, 33, 34793488 (1998). https://doi.org/10.1023/A:1013222421843 
[7] Bucknall C. B., Partridge I. K.: Phase separation in epoxy resins containing polyethersulphone. Polymer, 24, 639-644 (1983).

https://doi.org/10.1016/0032-3861(83)90120-9

[8] Raghava R. S.: Development and characterization of thermosetting-thermoplastic polymer blends for applications in damage-tolerant composites. Journal of Polymer Science Part B: Polymer Physics, 26, 65-81 (1988). https://doi.org/10.1002/polb.1988.090260103

[9] Bucknall C. B., Gilbert A. H.: Toughening tetrafunctional epoxy resins using polyetherimide. Polymer, 30, 213-217 (1989).

https://doi.org/10.1016/0032-3861(89)90107-9

[10] Hedrick J. L., Yilgor I., Jurek M., Hedrick J. C., Wilkes G. L., McGrath J. E.: Chemical modification of matrix resin networks with engineering thermoplastics: 1. Synthesis, morphology, physical behaviour and toughening mechanisms of poly(arylene ether sulphone) modified epoxy networks. Polymer, 32, 2020-2032 (1991). https://doi.org/10.1016/0032-3861(91)90168-I

[11] Kishi H., Odagiri N.: Toughened thermoset resin matrix composites. in 'Aerospace materials' (eds.: Cantor B., Grant P., Assender H.) Institute of Physics Publishing, Bristol, Chapter 14, 187-198 (2001). https://doi.org/10.1201/9781420034721.ch14

[12] Yamanaka K., Inoue T.: Structure development in epoxy resin modified with poly(ether sulphone). Polymer, 30, 662-667 (1989). https://doi.org/10.1016/0032-3861(89)90151-1

[13] Yamanaka K., Takagi Y., Inoue T.: Reaction-induced phase separation in rubber-modified epoxy resins. Polymer, 30, 1839-1844 (1989). https://doi.org/10.1016/0032-3861(89)90355-8

[14] Williams R. J. J., Rozenberg B. A., Pascault J-P.: Reaction-induced phase separation in modified thermosetting polymers. in 'Polymer analysis polymer physics' (eds.: Abe A., Albertsson A-C., Coates G. W., Genzer J., Kobayashi S., Lee K-S., Leibler L., Long T. E., Möller M., Okay O., Percec V., Tang B. Z., Terentjev E. M., Theato P., Vicent M. J., Voit B., Wiesner U., Zhang X.) Springer, Berlin, Vol 128, 95-156 (1997).

https://doi.org/10.1007/3-540-61218-1_7

[15] Hillmyer M. A., Lipic P. M., Hajduk D. A., Almdal K., Bates F. S.: Self-assembly and polymerization of epoxy resin-amphiphilic block copolymer nanocomposites. Journal of the American Chemical Society, 119, 2749 2750 (1997).

https://doi.org/10.1021/ja963622m

[16] Lipic P. M., Bates F. S., Hillymer M. A.: Nanostructured thermosets from self-assembled amphiphilic block copolymer/epoxy resin mixtures. Journal of the American Chemical Society, 120, 8963-8970 (1998). https://doi.org/10.1021/ja981544s

[17] Mijovic J., Shen M., Sy J. W., Mondragon I.: Dynamics and morphology in nanostructured thermoset network/ block copolymer blends during network formation. Macromolecules, 33, 5235-5244 (2000).

https://doi.org/10.1021/ma991894e
[18] Dean J. M., Lipic P. M., Grubbs R. B., Cook R. F., Bates F. S.: Micellar structure and mechanical properties of block copolymer-modified epoxies. Journal of Polymer Science Part B: Polymer Physics, 39, 2996-3010 (2001). https://doi.org/10.1002/polb.10062

[19] Guo Q., Thomann R., Gronski W.: Phase behavior, crystallization, and hierarchical nanostructures in selforganized thermoset blends of epoxy resin and amphiphilic poly(ethylene oxide)-block-poly(propylene oxide)-block-poly(ethylene oxide) triblock copolymers. Macromolecules, 35, 3133-3144 (2002). https://doi.org/10.1021/ma011971h

[20] Dean J. M., Verghese N. E., Pham H. Q., Bates F. S.: Nanostructure toughened epoxy resins. Macromolecules, 36, 9267-9270 (2003).

https://doi.org/10.1021/ma034807y

[21] Dean J. M., Grubbs R. B., Saad W., Cook R. F., Bates F. S.: Mechanical properties of block copolymer vesicle and micelle modified epoxies. Journal of Polymer Science Part B: Polymer Physics, 41, 2444-2456 (2003). https://doi.org/10.1002/polb.10595

[22] Wu J., Thio Y. S., Bates F. S.: Structure and properties of PBO-PEO diblock copolymer modified epoxy. Journal of Polymer Science Part B: Polymer Physics, 43, 1950-1965 (2005).

https://doi.org/10.1002/polb.20488

[23] Ritzenthaler S., Court F., David L., Girard-Reydet E., Leibler L., Pascault J. P.: ABC triblock copolymers/ epoxy-diamine blends. 1. Keys to achieve nanostructured thermosets. Macromolecules, 35, 6245-6254 (2002). https://doi.org/10.1021/ma0121868

[24] Ritzenthaler S., Court F., Girard-Reydet E., Leibler L., Pascault J. P.: ABC triblock copolymers/epoxy-diamine blends. 2. Parameters controlling the morphologies and properties. Macromolecules, 36, 118-126 (2003). https://doi.org/10.1021/ma0211075

[25] Maiez-Tribut S., Pascault J. P., Soulé E. R., Borrajo J., Williams R. J.: Nanostructured epoxies based on the self-assembly of block copolymers: A new miscible block that can be tailored to different epoxy formulations. Macromolecules, 40, 1268-1273 (2007). https://doi.org/10.1021/ma0621851

[26] Gerard P., Boupat N. P., Fine T., Gervat L., Pascault JP.: Toughness properties of lightly crosslinked epoxies using block copolymers. Macromolecular Symposia, 256, 55-64 (2007). https://doi.org/10.1002/masy.200751006

[27] Rebizant V., Abetz V., Tournilhac F., Court F., Leibler L.: Reactive tetrablock copolymers containing glycidyl methacrylate. Synthesis and morphology control in epoxyamine networks. Macromolecules, 36, 9889-9896 (2003). https://doi.org/10.1021/ma0347565

[28] Rebizant V., Venet A. S., Tournilhac F., Girard-Reydet E., Navarro C., Pascault J-P.: Chemistry and mechanical properties of epoxy-based thermosets reinforced by reactive and nonreactive SBMX block copolymers. Macromolecules, 37, 8017-8027 (2004). https://doi.org/10.1021/ma0490754 
[29] Serrano E., Tercjak A., Ocando C., Larrañaga M., Parellada M. D., Corona-Galván S., Mecerreyes D., Zafeiropoulos N. E., Stamm M., Mondragon I.: Curing behavior and final properties of nanostructured thermosetting systems modified with epoxidized styrenebutadiene linear diblock copolymers. Macromolecular Chemistry and Physics, 208, 2281-2292 (2007).

https://doi.org/10.1002/macp.200700169

[30] Meng F., Zheng S., Zhang W., Li H., Liang Q.: Nanostructured thermosetting blends of epoxy resin and amphiphilic poly( $\varepsilon$-caprolactone)-block-polybutadieneblock-poly( $\varepsilon$-caprolactone) triblock copolymer. Macromolecules, 39, 711-719 (2006).

https://doi.org/10.1021/ma0518499

[31] Meng F., Zheng S., Li H., Liang Q., Liu T.: Formation of ordered nanostructures in epoxy thermosets: A mechanism of reaction-induced microphase separation. Macromolecules, 39, 5072-5080 (2006). https://doi.org/10.1021/ma060004+

[32] Yu R., Zheng S.: Morphological transition from spherical to lamellar nanophases in epoxy thermosets containing poly(ethylene oxide)-block-poly(e-caprolactone)-block-polystyrene triblock copolymer by hardeners. Macromolecules, 44, 8546-8557 (2011). https://doi.org/10.1021/ma201456x

[33] Yu R., Zheng S., Li X., Wang J.: Reaction-induced microphase separation in epoxy thermosets containing block copolymers composed of polystyrene and poly $(\varepsilon-$ caprolactone): Influence of copolymer architectures on formation of nanophases. Macromolecules, 45, 9155 9168 (2012).

https://doi.org/10.1021/ma3017212

[34] Blanco M., López M., Kortaberria G., Mondoragon I.: Nanostructured thermosets from self-assembled amphiphilic block copolymer/epoxy resin mixtures: Effect of copolymer content on nanostructures. Polymer International, 59, 523-528 (2009).

https://doi.org/10.1002/pi.2731

[35] Romeo H. E., Zucchi I. A., Rico M., Hoppe C. E., Williams J. J.: From spherical micelles to hexagonally packed cylinders: The cure cycle determines nanostructures generated in block copolymer/epoxy blends. Macromolecules, 46, 4854-4861 (2013). https://doi.org/10.1021/ma400778s

[36] Cano L., Gutierrez J., Tercjak A.: Enhancement of the mechanical properties at the macro and nanoscale of thermosetting systems modified with a polystyreneblock-polymethyl methacrylate block copolymer. RSC Advances, 5, 102085-102095 (2015).

https://doi.org/10.1039/c5ra21857h
[37] Kishi H., Kunimitsu Y., Imade J., Oshita S., Morishita Y., Asada M.: Nano-phase structures and mechanical properties of epoxy/acryl triblock copolymer alloys. Polymer, 52, 760-768 (2011). https://doi.org/10.1016/j.polymer.2010.12.025

[38] Kishi H., Kunimitsu Y., Nakashima Y., Abe T., Imade J., Oshita S., Morishita Y., Asada M.: Control of nanostructures generated in epoxy matrices blended with PMMA- $b$-PnBa- $b$-PMMA triblock copolymers. Express Polymer Letters, 9, 23-35 (2015).

https://doi.org/10.3144/expresspolymlett.2015.4

[39] Asada M., Oshita S., Morishita Y., Nakashima Y., Kunimitsu Y., Kishi H.: Effect of miscible PMMA chain length on disordered morphologies in epoxy/PMMA$b$-PnBa- $b$-PMMA blends by in situ simultaneous SAXS/ DSC. Polymer, 105, 172-179 (2016).

https://doi.org/10.1016/j.polymer.2016.10.025

[40] Liu J., Sue H-J., Thompson Z. J., Bates F. S., Dettloff M., Jacob G., Verghese N., Pham H.: Nanocavitation in self-assembled amphiphilic block copolymer-modified epoxy. Macromolecules, 41, 7616-7624 (2008).

https://doi.org/10.1021/ma801037q

[41] Thompson Z. J., Hillymer M. A., Liu J., Sue H-J., Dettloff M., Bates F. S.: Block copolymer toughened epoxy: Role of cross-link density. Macromolecules, 42, 2333-2335 (2009). https://doi.org/10.1021/ma900061b

[42] Liu J., Thompson Z. J., Sue H-J., Bates F. S., Hillymer M. A., Dettloff M., Jacob G., Verghese N., Pham H.: Toughening of epoxies with block copolymer micelles of wormlike morphology. Macromolecules, 43, 72387243 (2010). https://doi.org/10.1021/ma902471g

[43] Okamoto T., Takayanagi M.: Application of two-phase mechanical model to viscoelastic properties of blends of high-density and low-density polyethylene. Journal of Polymer Science: Polymer Symposia, 23, 597-606 (1968). https://doi.org/10.1002/polc.5070230215

[44] Nielsen L. E.: Generalized equation for the elastic moduli of composite materials. Journal of Applied Physics, 41, 4626-4627 (1970). https://doi.org/10.1063/1.1658506

[45] Nielsen L. E.: Morphology and the elastic modulus of block polymers and polyblends. Rheologica Acta, 13, 86-92 (1974). https://doi.org/10.1007/BF01526889

[46] Veenstra H., Verkooijen P. C. J., van Lent B. J. J., Dam J. V., de Boer A. P., Nijhof A. P. H. J.: On the mechanical properties of co-continuous polymer blends: experimental and modelling. Polymer, 41, 1817-1826 (2000). https://doi.org/10.1016/S0032-3861(99)00337-7 